\title{
Hepatosplanchnic haemodynamics and renal blood flow and function in rats with liver failure
}

P Javlé, J Yates, H G Kynaston, K F Parsons, S A Jenkins

\begin{abstract}
Background-Massive liver necrosis, characteristic of acute liver failure, may affect hepatosplanchnic haemodynamics, and contribute to the alterations in renal haemodynamics and function.

Aims-To investigate the relation between hepatosplanchnic haemodynamics, including portal systemic shunting, and renal blood flow and function in rats with acute liver failure.

Methods-Liver failure was induced in male Wistar rats by intraperitoneal injection of $1.1 \mathrm{~g} / \mathrm{kg}$ of $\mathrm{D}(+)$-galactosamine hydrochloride. The parameters assessed included: systemic, hepatosplanchnic, and renal blood flow $\left({ }^{57} \mathrm{Co}\right.$ microsphere method); portal-systemic shunting and intrarenal shunting (consecutive intrasplenic, intraportal, or renal arterial injections of ${ }^{99 \mathrm{~m}}$ Tc methylene diphosphonate and ${ }^{99 \mathrm{~m}} \mathrm{Tc}$ albumin microspheres); arterial blood pressure and portal pressure; renal function; and liver function (liver function tests and ${ }^{14} \mathrm{C}$ aminopyrine breath test).

Results-Progressive liver dysfuntion was accompanied by the development of a hyperdynamic circulation, a highly significant decrease in renal blood flow and function, and an increase in intrarenal shunting 36, 42, and 48 hours after administration of $D$-galactosamine. The alterations in renal blood flow and function were accompanied by significant increases in portal pressure, portal venous inflow, and intrahepatic portal systemic shunting in galactosamine treated rats compared with controls. There was a significant correlation between changes in renal blood flow and changes in portal pressure, intrahepatic portal systemic shunting, and deterioration in liver function $(r=0.8$, p<0.0001).
\end{abstract}

Conclusions-The results of this study suggest that both increased intrahepatic portal systemic shunting and hepatocyte impairment may contribute to alterations in renal haemodynamics and function.

(Gut 1998;43:272-279)

Keywords: liver failure; hepatosplanchnic; systemic; renal; haemodynamics

Acute liver failure, characterised by severe hepatocyte injury or massive hepatic necrosis is accompanied by oliguric renal failure in approximately $50 \%$ of patients. ${ }^{1}$ Functional renal failure (hepatorenal syndrome) is usually present but acute tubular necrosis has also been reported. ${ }^{2}$ These changes in kidney function are accompanied by a reduction in renal blood flow and effective renal plasma flow secondary to decreased perfusion pressure, intrarenal vasoconstriction, increased intrarenal shunting, or a combination of these effects. ${ }^{3-6}$ Furthermore, acute liver failure is characterised by profound alterations in systemic haemodynamics including hypotension, a decrease in splanchnic vascular resistance, pooling of blood in the splanchnic circulation, a compensatory increase in cardiac output, and a supply dependent oxygen consumption indicative of an underlying tissue oxygen debt. ${ }^{6-10}$ The circulatory changes characteristic of acute liver failure resemble those observed in cirrhosis in some respects but differ in others. Thus, in cirrhosis and portal hypertension the characteristic hyperdynamic circulation and alterations in renal haemodynamics are thought to result from increased circulating levels of gut derived vasoactive agents which are normally removed by the liver, entering the systemic circulation as a consequence of impaired hepatocyte function and portal-systemic shunting (PSS). ${ }^{11-13}$ In contrast, in acute liver failure where there is no underlying chronic disease, the duration of the condition is considered to be too short for the development of significant PSS. Therefore, in acute liver failure, the increased systemic levels of the gut derived substances believed to be responsible for the changes in systemic and renal haemodynamics are thought to result primarily from the severe impairment of hepatic function. However, massive liver necrosis characteristic of acute liver failure, particularly the hyperacute form of the syndrome, may grossly affect hepatosplanchnic haemodynamics, and consequently contribute to the alterations in renal haemodynamics and function. As there is a paucity of data on the relation between hepatosplanchnic haemodynamics and PSS, and renal function and blood flow in acute liver failure we have carried out such a study in rats.

\section{Materials and methods}

EXPERIMENTAL DESIGN

Forty eight male Wistar rats (body weight 250-300 g), obtained from Harlan UK Ltd (Shaw's Farm, Blackthorn, Bicester, Oxon) received an intraperitoneal injection of $1.1 \mathrm{~g} / \mathrm{kg}$ of $\mathrm{D}(+)$-galactosamine hydrochloride (Sigma Chemical Corporation, St Louis, Missouri, USA) as a $100 \mathrm{mg} / \mathrm{ml}$ solution $(\mathrm{pH}$ 6.8) in normal saline. ${ }^{14} \mathrm{~A}$ control group of 48 rats received the same volume of normal saline. All animals were allowed access to a pelleted laboratory diet (CRM Labsure Animal Diets, K\&K Greef Ltd, Croydon) ad libitum throughout 
the study period. Control animals were allowed access to water, and galactosamine treated animals to $10 \%$ glucose solution ad libitum to maintain blood glucose levels.

The rats were randomly allocated to four groups of 12 animals each for investigation at $24,36,42$, and 48 hours after administration of either galactosamine or saline.

\section{HAEMODYNAMIC MEASUREMENTS}

At the time of study, the rats were anaesthetised by an intraperitoneal injection of pentobarbitone sodium $50 \mathrm{mg} / \mathrm{kg}$ (Sagatal, May \& Baker Ltd). Through a midline incision the portal vein was exposed, cannulated via an ileocolic branch, and the cannula advanced to just below the porta hepatis. The midline laparotomy was closed in two layers after placement of the portal venous cannula to reduce evaporative loss and conserve body heat. The spleen was exposed via a small left lateral incision for the intrasplenic injection of radionuclides for the measurement of total PSS. The left and right femoral arteries and the left femoral vein were cannulated with 2 FG Portex (Laboratoire Portex SA, France) cannulae. Arterial blood pressure and portal venous pressure were continuously monitored throughout the study by connecting the left femoral artery and portal venous cannulae via isolated pressure tranducers (Medex Ltd) and amplifier to a two channel recorder (MX2, Lectromed UK Ltd). Finally the right common carotid artery was exposed through a cervical incision and a $2 \mathrm{FG}$ polyethylene cannula was introduced into the carotid artery via an arteriotomy. The cannula was screened into the left ventricle using an image intensifier (Seimens Siremobile, Seimens Ltd, Sunbury-on-Thames, UK) so that its tip was approximately $1 \mathrm{~mm}$ below the aortic valve. Adequate expulsion of a small bolus of injectate by the left ventricle was confirmed by injecting $0.1 \mathrm{ml}$ of the contrast medium, sodium meglumine loxaglate $(320 \mathrm{mg} / \mathrm{ml}$; May \& Baker, Dagenham), via the catheter.

Portal-systemic shunting was determined by consecutive intrasplenic (or intraportal) injections of technetium- $99 \mathrm{~m}$ methylene diphosphonate (MDP) and ${ }^{99 \mathrm{~m}} \mathrm{Tc}$ albumin microspheres as previously described. ${ }^{15}$ In brief, when the animals were haemodynamically stable, a straight bore sodium iodide scintillation counter linked to a scalemeter and computer (Spherex monitoring system, Pharmacia, Sweden) was placed over the rat's thorax and shielded from the liver by a lead screen. The increase in count rate in the lung field of interest was calculated as the difference between the plateau level before each injection of the isotope and the baseline level. The baseline level was determined from the mean of the count rate during the 30 seconds immediately before the start of each injection. The plateau level was calculated as the mean count rate during 60 seconds (the average number of counts per second for six consecutive 10 second periods during the stable phase) within three minutes from the time of each injection of the isotope. The count rate was corrected for the dose of radioisotope in each injection to obtain comparable values of the count rate per unit of radioactivity injected. The decay of ${ }^{99 \mathrm{~m}} \mathrm{Tc}\left(\mathrm{t}_{1 / 2}=6\right.$ hours) and the "dead time" of the detector were corrected for by the computer software to obtain a linear response up to a maximum count rate of $60000 \mathrm{cps}$. Intrahepatic PSS was measured by injecting $20 \mu \mathrm{l}(100 \mathrm{Mbq} /$ $\mathrm{ml})$ of ${ }^{99 \mathrm{~m}} \mathrm{Tc}$ MDP followed by a $20 \mu \mathrm{l}$ saline chaser via the portal venous cannula. As ${ }^{99 \mathrm{~m}} \mathrm{Tc}$ MDP is not retained within the liver, the majority passes to the lungs and is registered graphically as the $100 \%$ passing fraction. The ${ }^{99 \mathrm{~m}}$ Tc MDP therefore acts as a reference injection. Following injection of ${ }^{99 \mathrm{~m}} \mathrm{Tc}$ MDP, 20 $\mu \mathrm{l}(100 \mathrm{MBq} / \mathrm{ml})$ of vortex mixed ${ }^{99 \mathrm{~m}} \mathrm{Tc}$ albumin microspheres (mean diameter $20 \mu \mathrm{m}$; Sferotonic-S, Sorin Biomedica, Italy), were administered via the portal venous cannula, again followed by a $20 \mu \mathrm{l}$ saline chaser. Previous preliminary studies indicated that this volume of chaser ensures that all the isotope is washed out of the cannula into the portal vein. Unlike ${ }^{99 \mathrm{~m}} \mathrm{Tc}$ MDP, the ${ }^{99 \mathrm{~m}} \mathrm{Tc}$ albumin microspheres are trapped within the liver sinusoids and only those passing through the liver via the PSS appear in the lung field of interest. The percentage of the passing fraction of ${ }^{99 \mathrm{~m}} \mathrm{Tc}$ albumin microspheres is expressed as a passing fraction of the reference injection of ${ }^{99 \mathrm{~m}}$ Tc MDP. Total PSS was determined by consecutive intrasplenic injections of ${ }^{99 \mathrm{~m}}$ Tc MDP and ${ }^{99 \mathrm{~m}} \mathrm{Tc}$ albumin microspheres. Extrahepatic PSS was calculated by subtracting the intrahepatic PSS from the total PSS. Previous studies have indicated an excellent correlation $(r=0.94)$ between this method of measuring intrahepatic and total PSS and that evaluated by the more classic method using nonbiodegradable microspheres. ${ }^{15}$

Intrarenal shunting was determined by a modification of the methodology used to determine PSS. Briefly, $20 \mu \mathrm{l}(100 \mathrm{Mbq} / \mathrm{ml})$ of ${ }^{99 \mathrm{~m}}$ Tc MDP was administered into the renal artery, the descending aorta distal to the renal artery being temporarily occluded by a snug ligature during injection of the isotopes. As ${ }^{99 \mathrm{~m}} \mathrm{Tc}$ MDP is not retained within the kidney, the majority passes to the lungs and is registered graphically as the $100 \%$ passing fraction. The ${ }^{99 \mathrm{~m}} \mathrm{Tc}$ MDP therefore acts as a reference injection. Following injection of ${ }^{99 \mathrm{~m}} \mathrm{Tc} \mathrm{MDP}, 20 \mu \mathrm{l}(100 \mathrm{MBq} / \mathrm{ml})$ of vortex mixed ${ }^{99 \mathrm{~m}} \mathrm{Tc}$ albumin microspheres (mean diameter $20 \mu \mathrm{m}$ ) were administered into the renal artery. Unlike ${ }^{99 \mathrm{~m}} \mathrm{Tc}$ MDP, the ${ }^{{ }^{99 m}} \mathrm{Tc}$ albumin microspheres are trapped in the renal capillary bed and only those passing through the intrarenal arteriovenous shunts appear in the lung field of interest. The percentage of the passing fraction of ${ }^{99 \mathrm{~m}} \mathrm{Tc}$ albumin microspheres was expressed as a passing fraction of the reference injection of ${ }^{99 \mathrm{~m}} \mathrm{Tc}$ MDP.

Hepatic, splanchnic, and renal blood flow was determined according to the method of McDevitt and Nies. ${ }^{16}$ In brief, the right femoral artery cannula was connected to a SAGE 351 (Orion Research Inc., Cambridge, Massachusetts, USA) withdrawal pump. A reference blood sample was withdrawn from the right femoral artery over a 90 second period at a rate of 0.6 $\mathrm{ml} / \mathrm{min}$. Ten seconds after the start of blood withdrawal each rat received an intraventricular 
Table 1 Liver function tests after injection of D-galactosamine or saline (control)

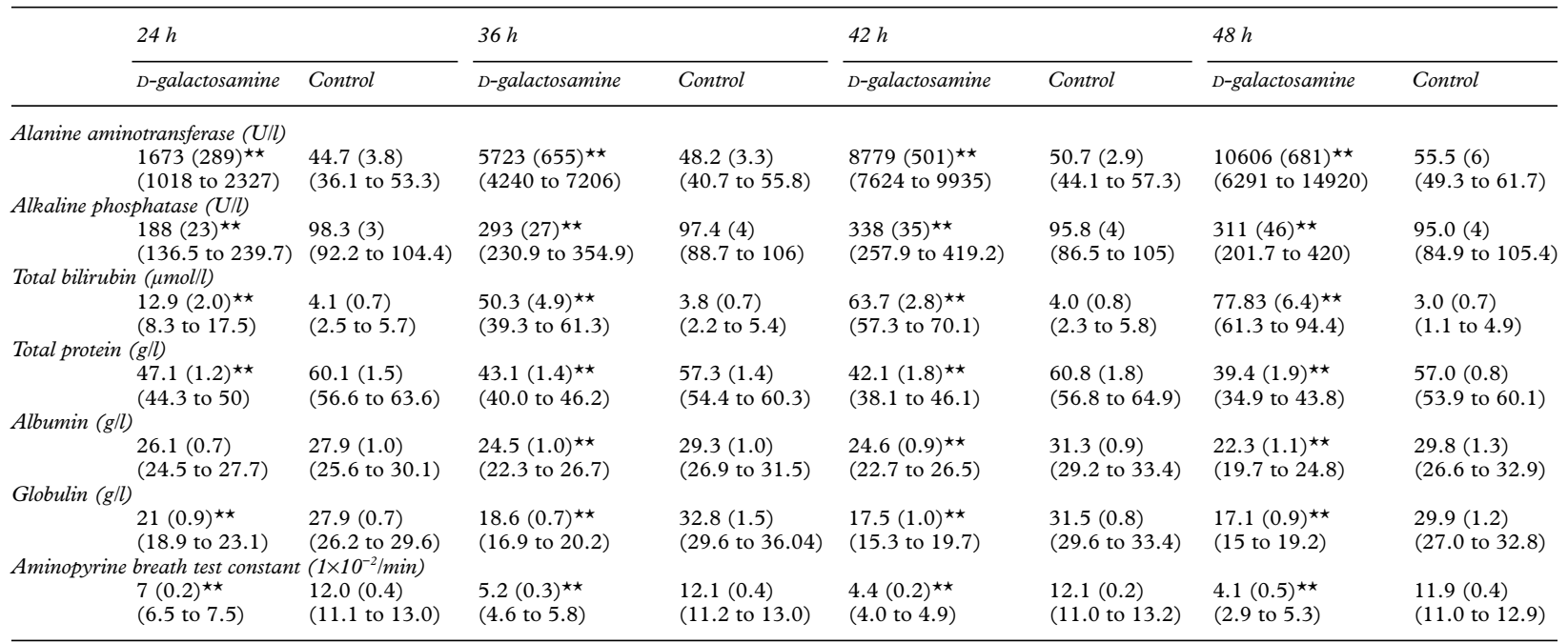

Results are expressed as mean (SEM) (95\% confidence interval).

$\star \star \mathrm{p}<0.01$.

injection of approximately $2-4 \times 10^{5}$ cobalt -57 labelled carbonised microspheres (mean diameter $15 \mu \mathrm{m}$ ) suspended in $0.9 \%$ normal saline with $0.1 \%$ of Tween 80 (NEN-Trac, DuPont) in $0.6 \mathrm{ml}$ over a period of 20 seconds using a constant rate infusion pump (SAGE 351, Orion Research Inc., Cambridge, Massachusetts, USA). Prior to injection the microspheres were sonicated for 10 minutes and then vortex mixed immediately before injection to ensure their complete disaggregation. To ensure that the withdrawal of a reference blood sample from the femoral artery cannula did not alter the arterial blood pressure, saline was infused through the left femoral venous cannula at the same rate as blood withdrawal.

After completion of all the studies the animals were killed with an anaesthetic overdose, and the organs were excised, weighed, placed in counting vials, and stored at $4^{\circ} \mathrm{C}$ for seven days until all the ${ }^{99 \mathrm{~m}} \mathrm{Tc}$ had decayed to an insignificant amount. The half life of ${ }^{99 \mathrm{~m}} \mathrm{Tc}$ is six hours and consequently most will have decayed after 48 hours. In contrast, the half life of ${ }^{57} \mathrm{Co}$ is 6520.8 hours and only a negligible decay of this isotope occurs before almost all the ${ }^{99 \mathrm{~m}} \mathrm{Tc}$ has disappeared. The vials were placed in a Canberra Packard 500 automatic gamma well counter and the radioactivity counted. Cardiac output and organ blood flow were determined by the method of McDevitt and Nies. ${ }^{16}$

From the relative counts in the various organs the regional blood flow and cardiac output were calculated. The radioactivity of the reference blood sample was used to calculate the cardiac output ( $\mathrm{ml} / \mathrm{min})$ using the formula:

Cardiac output $=$ injected activity $\times$ reference withdrawal rate reference activity

Injected activity and reference activity are expressed as cpm and reference withdrawal rate as $\mathrm{ml} / \mathrm{min}$.

Individual organ blood flow was determined using the formula:

Organ blood flow $=$ organ activity $\times$ reference withdrawal rate reference activity

Organ activity and reference activity are expressed as cpm and organ blood flow and reference withdrawal rate as $\mathrm{ml} / \mathrm{min}$.

Portal venous inflow was calculated by adding together the flows to the stomach, small and large bowel, pancreas, mesentery, and spleen.

Table 2 Circulatory and renal biochemical changes after injection of D-galactosamine or saline (control)

\begin{tabular}{|c|c|c|c|c|c|c|c|}
\hline \multicolumn{2}{|l|}{$24 h$} & \multicolumn{2}{|l|}{$36 h$} & \multicolumn{2}{|l|}{$42 h$} & \multicolumn{2}{|l|}{$48 h$} \\
\hline D-galactosamine & Control & D-galactosamine & Control & D-galactosamine & Control & D-galactosamine & Control \\
\hline \multicolumn{8}{|l|}{ Arterial blood pressure $(\mathrm{mm} \mathrm{Hg}$ ) } \\
\hline $\begin{array}{l}91.8(3.6) \\
(83.6 \text { to } 100)\end{array}$ & $\begin{array}{l}98.4(2.4) \\
(93 \text { to } 104)\end{array}$ & $\begin{array}{l}88(4.7) \\
(77.5 \text { to } 98.5)\end{array}$ & $\begin{array}{l}95.6(2.7) \\
(89.6 \text { to } 101.6)\end{array}$ & $\begin{array}{l}87.4(3.0) \\
(80.5 \text { to } 94.3)\end{array}$ & $\begin{array}{l}95.4(2.4) \\
(90 \text { to } 101)\end{array}$ & $\begin{array}{l}82.5(3.6) \\
(73.3 \text { to } 91.7)\end{array}$ & $\begin{array}{l}96.2(3) \\
(88 \text { to } 105)\end{array}$ \\
\hline \multicolumn{8}{|l|}{ Peripheral vascular resistance } \\
\hline $\begin{array}{l}1.27(0.05) \\
(1.16 \text { to } 1.38)\end{array}$ & $\begin{array}{l}1.4(0.03) \\
(1.3 \text { to } 1.47)\end{array}$ & $\begin{array}{l}1.05(0.07)^{\star \star} \\
(0.89 \text { to } 1.2)\end{array}$ & $\begin{array}{l}1.43(0.05) \\
(1.32 \text { to } 1.53)\end{array}$ & $\begin{array}{l}0.99(0.06)^{\star \star} \\
(0.86 \text { to } 1.13)\end{array}$ & $\begin{array}{l}1.37(0.04) \\
(1.28 \text { to } 1.45)\end{array}$ & $\begin{array}{l}0.98(0.04)^{\star \star} \\
(0.88 \text { to } 1.07)\end{array}$ & $\begin{array}{l}1.4(0.05) \\
(1.3 \text { to } 1.56)\end{array}$ \\
\hline \multicolumn{8}{|l|}{ Serum urea $(\mathrm{mmol} / \mathrm{l})$} \\
\hline $\begin{array}{l}7.7(0.6) \\
(6.3 \text { to } 9.2)\end{array}$ & $\begin{array}{l}6.4(0.4) \\
(5.5 \text { to } 7.3)\end{array}$ & $\begin{array}{l}10.7(0.6)^{\star \star} \\
(9.3 \text { to } 12.1)\end{array}$ & $\begin{array}{l}6.4(0.4) \\
(5.5 \text { to } 7.3)\end{array}$ & $\begin{array}{l}13.9(0.8)^{\star \star} \\
(12.0 \text { to } 15.8)\end{array}$ & $\begin{array}{l}6.4(0.2) \\
(5.9 \text { to } 6.9)\end{array}$ & $\begin{array}{l}14.6(0.8)^{\star \star} \\
(12.5 \text { to } 16.6)\end{array}$ & $\begin{array}{l}6.6(0.4) \\
(5.5 \text { to } 7.6)\end{array}$ \\
\hline \multicolumn{8}{|l|}{ Serum creatinine $(\mu m o l / l)$} \\
\hline $\begin{array}{l}59.1(3.8) \\
(50.5 \text { to } 67.7)\end{array}$ & $\begin{array}{l}55(1.4) \\
(51.8 \text { to } 58.2)\end{array}$ & $\begin{array}{l}94.6(2.2)^{\star \star} \\
(89.6 \text { to } 99.6)\end{array}$ & $\begin{array}{l}57.8(2.1) \\
(53.2 \text { to } 62.4)\end{array}$ & $\begin{array}{l}105.5(2.6)^{\star \star} \\
(99.6 \text { to } 111.4)\end{array}$ & $\begin{array}{l}59.3(1.9) \\
(55 \text { to } 63.6)\end{array}$ & $\begin{array}{l}115.8(2.9)^{\star \star} \\
(108.4 \text { to } 123.3)\end{array}$ & $\begin{array}{l}58(1.5) \\
(53.7 \text { to } 61.6)\end{array}$ \\
\hline
\end{tabular}

Results are expressed as mean (SEM) (95\% confidence interval).

${ }^{\star \star} \mathrm{p}<0.01$. 

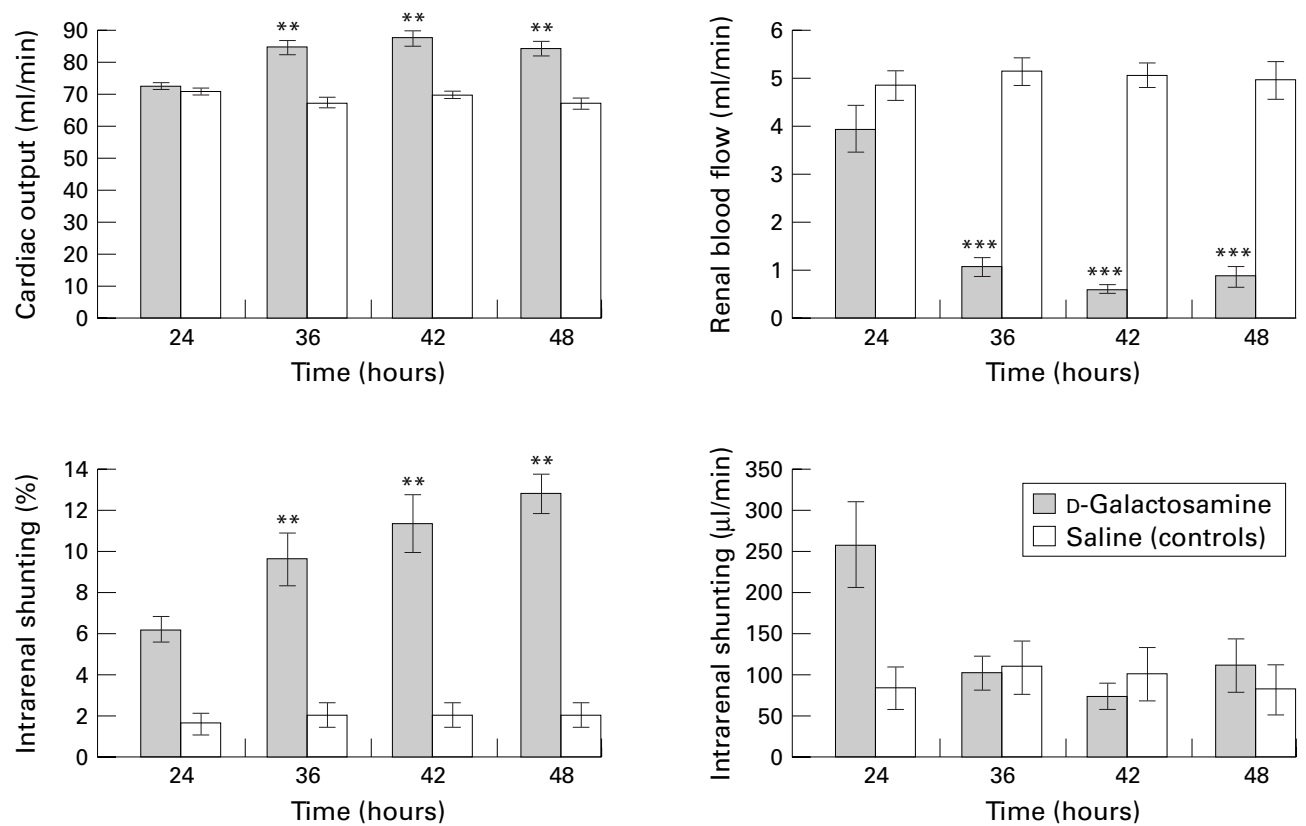

Figure 1 Changes in circulatory and renal haemodynamics after injection of D-galactosamine or saline. Results are expressed as mean (SEM). ${ }^{\star \star} p<0.01,{ }^{\star \star \star} p<0.001$.

If the blood flow to the right and the left kidney differed by more than $10 \%$ the distribution of microspheres was not considered to be uniform and the results discarded.

\section{BIOCHEMICAL STUDIES}

Heparinised blood samples $(0.2 \mathrm{ml})$ were obtained from the tail artery of all animals before administration of galactosamine (or saline) under light ether anaesthesia. Further blood samples were obtained from the femoral artery cannula $24,36,42$, and 48 hours after galactosamine or saline administration. The samples were centrifuged at $4^{\circ} \mathrm{C}$ and $2000 \mathrm{~g}$ for 10 minutes and the plasma was analysed on a discrete multiple channel analyser (CXT Beckman, High Wycombe, UK).

AMINOPYRINE BREATH TEST

The aminopyrine breath test was used to assess liver function before and after intraperitoneal injection of galactosamine or saline. Each rat received $15 \mathrm{KBq}$ of diethylamine $-{ }^{14} \mathrm{C}$ aminopyrine (Amersham Corp., Arlington Heights, Illinois) in a volume of $100 \mu \mathrm{l}$ intraperitoneally. The animals were housed in an airtight container through which air was pumped using a constant infusion pump. The exhaled ${ }^{14} \mathrm{CO}_{2}$ was collected in 15 minute breath samples for 120 minutes starting 60 minutes after aminopyrine administration. ${ }^{17}$ The radioactivity was counted in an Isocap 300 liquid scintillation system (Nuclear Data Inc., Medical Division, Chicago, Illinois, USA). The aminopyrine breath test constant (ABT-k) was calculated by least square regression analysis of the logarithm of counts versus time. ${ }^{18}$

\section{STATISTICAL ANALYSIS}

The results are presented as mean (SEM) together with $95 \%$ confidence intervals (CI). Comparisons between groups were made by one way analysis of variance (ANOVA) using a modified (Boneferroni) $t$ test. Any correlation between changes in hepatosplanchnic haemodynamics and function and renal haemodynamics and function was determined using multiple regression analysis.

\section{Results}

LIVER FUNCTION TESTS

Plasma bilirubin and liver enzyme concentrations rose progressively in rats treated with galactosamine and were significantly increased

Table 3 Changes in hepatic arterial flow and extrahepatic portal-systemic shunting after injection of D-galactosamine or saline (control)

\begin{tabular}{|c|c|c|c|c|c|c|c|}
\hline \multicolumn{2}{|l|}{$24 h$} & \multicolumn{2}{|l|}{$36 h$} & \multicolumn{2}{|l|}{$42 h$} & \multicolumn{2}{|l|}{$48 h$} \\
\hline D-galactosamine & Control & D-galactosamine & Control & D-galactosamine & Control & D-galactosamine & Control \\
\hline \multicolumn{8}{|l|}{ Hepatic arterial flow $(\mathrm{ml} / \mathrm{min})$} \\
\hline $\begin{array}{l}1.8(0.5) \\
(0.6 \text { to } 3)\end{array}$ & $\begin{array}{l}1.5(0.5) \\
(1.2 \text { to } 1.8)\end{array}$ & $\begin{array}{l}0.78(0.1) \\
(0.5 \text { to } 1.1)\end{array}$ & $\begin{array}{l}1.5(0.1) \\
(1.2 \text { to } 1.8)\end{array}$ & $\begin{array}{l}0.69(0.2) \\
(0.3 \text { to } 1.0)\end{array}$ & $\begin{array}{l}1.5(0.2) \\
(1.0 \text { to } 1.9)\end{array}$ & $\begin{array}{l}0.8(0.1) \\
(0.4 \text { to } 1.1)\end{array}$ & $\begin{array}{l}1.3(0.1) \\
(1.0 \text { to } 1.7)\end{array}$ \\
\hline \multicolumn{8}{|c|}{ Extrahepatic portal-systemic shunting (\%) } \\
\hline $\begin{array}{l}1.0(0.9) \\
(0.7 \text { to } 2.7)\end{array}$ & $\begin{array}{l}2.0(0.6) \\
(0.3 \text { to } 2.5)\end{array}$ & $\begin{array}{l}1.6(0.7) \\
(0.7 \text { to } 2.3)\end{array}$ & $\begin{array}{l}1.4(0.6) \\
(0.8 \text { to } 2.1)\end{array}$ & $\begin{array}{l}1.3(0.6) \\
(0.3 \text { to } 2.9)\end{array}$ & $\begin{array}{l}1.8(0.4) \\
(0.9 \text { to } 2.7)\end{array}$ & $\begin{array}{l}2.9(0.5) \\
(2.1 \text { to } 3.2)\end{array}$ & $\begin{array}{l}1.3(0.9) \\
(0.7 \text { to } 3.3)\end{array}$ \\
\hline \multicolumn{8}{|c|}{ Extrahepatic portal-systemic shunting ( $\mathrm{ml} / \mathrm{min})$} \\
\hline $0.12(0.03)$ & $0.2(0.002)$ & $0.18(0.002)$ & $0.13(0.002)$ & $0.17(0.006)$ & $\begin{array}{l}0.15 \\
(0.002)\end{array}$ & $0.29(0.005)$ & $\begin{array}{l}0.11 \\
(0.005)\end{array}$ \\
\hline$(0.08$ to 0.3$)$ & $(0.02$ to 0.3$)$ & $(0.07$ to 0.29$)$ & $(0.07$ to 0.22$)$ & $(0.03$ to 0.44$)$ & $\begin{array}{l}(0.07 \text { to } \\
0.3)\end{array}$ & $(0.16$ to 0.4$)$ & $\begin{array}{l}(0.05 \text { to } \\
0.33)\end{array}$ \\
\hline
\end{tabular}

Results are expressed as mean (SEM) (95\% confidence interval). 

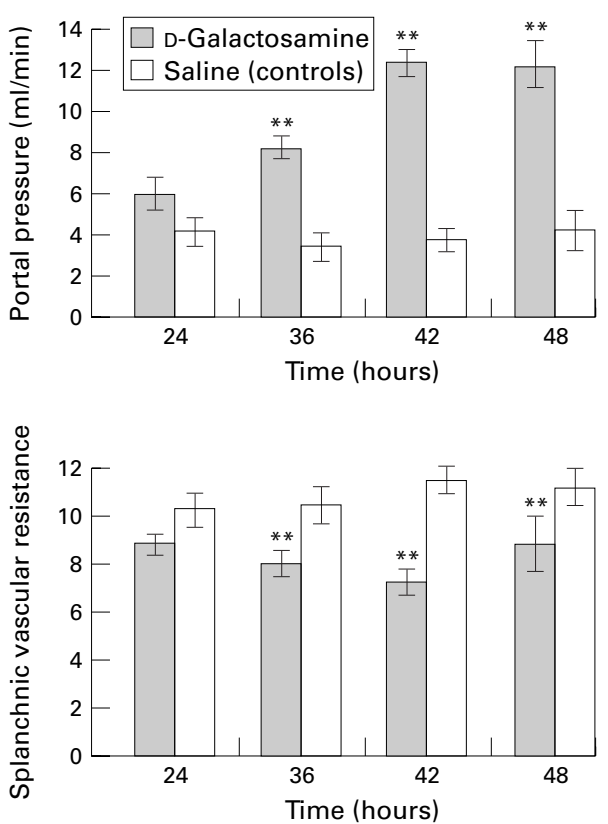

$(\mathrm{p}<0.0001$; ANOVA $)$ above those observed in controls 24, 36, 42, and 48 hours after administration of the hepatotoxin (table 1). The increases in plasma concentrations of bilirubin and liver enzymes were maximal 42 hours after galactosamine administration and no further increases were observed thereafter $(p=0.04$; modified $t$ test).

A progressive decrease ( $\mathrm{p}<0.0001$; ANOVA) in the ABT-k was observed 24, 36, 42, and 48 hours following galactosamine administration compared with controls (table 1). There was a highly significant correlation between the increases in the concentrations of serum bilirubin and liver enzymes and the reduction in the ABT-k $(r=0.84, \mathrm{p}<0.0001$; multiple linear regression).

SYSTEMIC HAEMODYNAMICS

Although progressive liver failure induced by galactosamine was associated with decreases in the arterial blood pressure 36, 42 , and 48 hours after administration of the hepatotoxin (table 2 ), the changes were not statistically significant $(p=0.3$; ANOVA $)$. In contrast, there was a significant increase in cardiac output (fig 1) and a decrease in peripheral vascular resistance (table 2) 36, 42, and 48 hours following galactosamine administration compared with controls $(\mathrm{p}<0.001$; ANOVA).

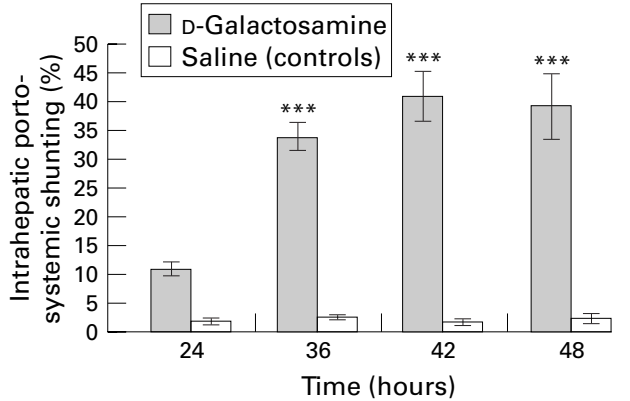

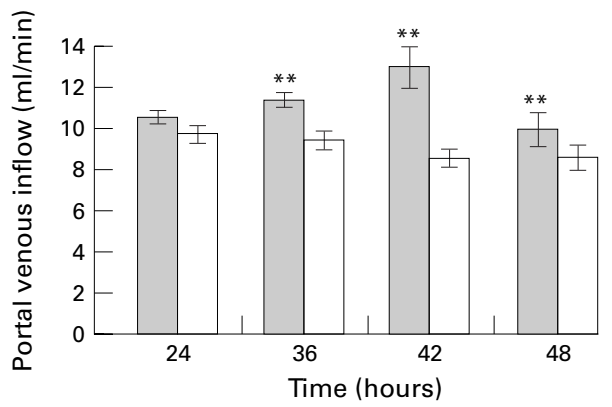

Figure 2 Changes in hepatosplanchnic haemodynamics after injection of D-galactosamine or saline. Results are expressed as mean (SEM). ${ }^{\star \star} p<0.01$.

RENAL HAEMODYNAMICS AND FUNCTION

Liver injury was associated with a progressive impairment in renal function as evidenced by highly significant increases in serum urea and creatinine concentrations 36,42 , and 48 hours after galactosamine administration (table 2). Although cardiac output increased with progressive liver failure, there was a highly significant decrease in renal blood flow accompanied by a significant increase $(\mathrm{p}<0.0001$; ANOVA) in intrarenal shunting (fig 1) 36, 42, and 48 hours after galactosamine administration. However, the absolute intrarenal shunt flow did not change significantly 36,42 , and 48 hours after galactosamine administration because of a significant decrease in renal blood flow (fig 1). The changes in renal haemodynamics were maximal 42 hours after galactosamine administration and no further significant changes (modified $t$ test) were observed for the duration of the study.

\section{HEPATOSPLANCHNIC HAEMODYNAMICS}

There were no significant changes in hepatic arterial flow in galactosamine treated rats compared with controls (table 3 ). In contrast, portal venous inflow and portal pressure were significantly increased and splanchnic vascular resistance decreased $(\mathrm{p}<0.001$; ANOVA) 36, 42 , and 48 hours following galactosamine

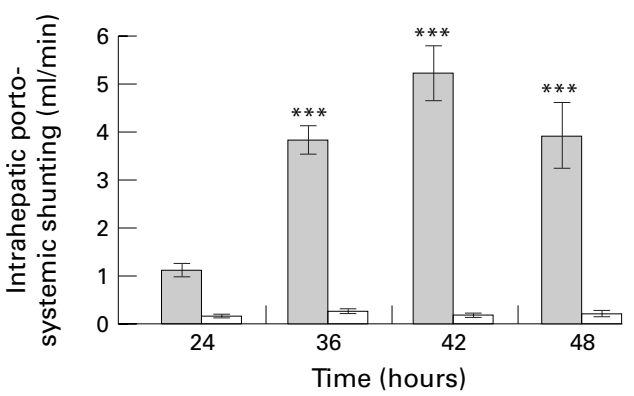

Figure 3 Changes in intrahepatic portal-systemic shunting after injection of D-galactosamine or saline. Results are expressed as mean (SEM). ${ }^{\star \star *} p<0.001$. 
administration compared with controls (fig 2). Furthermore, the degree of intrahepatic PSS was greatly increased $(\mathrm{p}<0.0001 ;$ ANOVA) 36, 42 , and 48 hours following galactosamine administration compared with controls (fig 3 ). In contrast, there was no significant extrahepatic PSS in either control or galactosamine treated rats (table 3 ). The hepatosplanchnic haemodynamics were maximally altered 42 hours after galactosamine administration and no further significant changes occurred thereafter (modified $t$ test).

There was a highly significant correlation $(r=0.84, \mathrm{p}<0.0001$; multiple linear regression) between the changes in renal blood flow and the increases in portal pressure $(p=0.007)$ and intrahepatic PSS $(\mathrm{p}<0.0001)$. There was no significant correlation between the decrease in arterial blood pressure and the reduction in renal blood flow $(p=0.3)$.

\section{Discussion}

Administration of the specific hepatotoxin $\mathrm{D}$-galactosamine to rats results in consistent toxic liver injury and liver failure. ${ }^{19}$ In the present study, progressive liver dysfunction was apparent 24 hours after administration of D-galactosamine as evidenced by increased plasma concentrations of liver enzymes and serum bilirubin and a decrease in plasma albumin concentrations. Maximal liver damage occurred 42 hours after administration of D-galactosamine and there were no further significant increases in plasma bilirubin concentrations and liver enzymes thereafter, for the duration of the study (48 hours). The aminopyrine breath test provides a quantitative measure of hepatic function in man and rats. ${ }^{20}{ }^{21}$ In the present study, there was a positive correlation between changes in ABT-k and alterations in plasma concentrations of bilirubin and liver enzymes and a negative correlation with the decreased plasma albumin. The results of this study are therefore in accord with previous observations which suggest that D-galactosamine administration to rats results in the development of a robust and reproducible model of acute liver failure. ${ }^{14}$

Thirty six hours after administration of D-galactosamine, the rats displayed features of a hyperdynamic circulation with an increased cardiac output, arterial hypotension, and a decrease in systemic vascular resistance, observations in accord with previous studies. ${ }^{22}$ The development of hyperdynamic circulation in galactosamine treated rats was accompanied by a deterioration in renal function 36 hours after administration of galactosamine, as evidenced by increasing plasma concentrations of urea and creatinine. Furthermore, the alterations in renal function were accompanied by a highly significant decrease in renal blood flow 36 hours after D-galactosamine administration, findings in accord with previous studies. ${ }^{23-25}$ The very large decrease in renal blood flow observed in the galactosamine treated rats could be due to either renal vasoconstriction ${ }^{6}$ or to a decrease in renal perfusion pressure. ${ }^{1}$ However, it seems unlikely that arterial hypotension was contributory to the observed decrease in renal perfusion as there was no significant correlation between changes in arterial blood pressure and renal haemodynamics. However, the reduction in renal perfusion in rats with galactosamine induced liver failure was accompanied by an increase in the relative degree of intrarenal shunting although the actual shunt flow did not change significantly. It has been suggested that renal hypoperfusion is accompanied by a redistribution of intrarenal blood flow. ${ }^{26}$ This hypothesis would appear to be supported by the results of the present study as renal hypoperfusion was accompanied by a significant increase in relative intrarenal shunting. However, the actual shunt flow did not change owing to renal hypoperfusion; only the percentage of total renal blood flow increased. These observations would suggest that during hypoperfusion, the size of the intrarenal shunts remains relatively constant; only the percentage of total blood passing through the shunt increases. Thus, the results of this study suggest that there is no redistribution of renal blood flow during hypoperfusion of the kidney, merely a relative increase in the percentage of blood passing through the intrarenal arteriovenous shunts.

The changes in renal haemodynamics observed in this study were associated with significant changes in hepatosplanchnic haemodynamics observed 36 hours after D-galactosamine administration. Thus, in this study galactosamine administration resulted in a significant increase in portal pressure and portal venous inflow, indicative of splanchnic pooling. This observation would support the hypothesis that in galactosamine induced liver failure, splanchnic pooling results in a decrease in effective blood volume, thereby reducing renal perfusion. ${ }^{27}$ There is however some controversy as to whether alterations in renal blood flow and function in liver disease are secondary to changes in hepatosplanchnic haemodynamics, in particular portal hypertension, or to deterioration in hepatic function. In experimental animals, a good correlation has been observed between the degree of portal hypertension and the reduction in renal perfusion which the authors attributed to a decreased glomerular filtration rate. ${ }^{28}$ In contrast, functional renal failure has never been correlated with the degree of portal hypertension in cirrhotic patients and furthermore, portacaval shunting does not improve renal function in the majority of patients undergoing such decompressive surgery. ${ }^{29}$ Other studies have shown that in cirrhotic rats, sodium retention, indicative of impairment of renal function, occurs when hepatic function decreases below a critical threshold. ${ }^{18} 3031$ However, it should also be pointed out that in the aforementioned studies, the induction of cirrhosis also resulted in portal hypertension and changes in splanchnic haemodynamics which may also provoke sodium retention. In the present study, the increases in portal pressure were accompanied by changes in portal venous inflow and a deterioration in liver function; we were therefore unable to ascertain whether portal hypertension per se or alterations 
in liver function were primarily responsible for alterations in renal blood flow and function.

The most significant finding of this study was perhaps a highly significant increase in intrahepatic portal systemic shunting 36 hours after galactosamine administration, which as far as we are aware has not been previously described in acute liver failure and may play a major role in the alterations in renal blood flow and function. Thus, in cirrhosis and portal hypertension, gastrointestinal derived vasodilatory substances, such as glucagon, vasoactive intestinal polypeptide, ${ }^{32}$ substance $\mathrm{P}^{33}$ vasodilatory prostaglandins $\left(\mathrm{PGE}_{2}\right.$ and prostacyclin), ${ }^{34}$ and endotoxins, ${ }^{35}$ which are normally removed by the liver, enter the systemic circulation via shunting through the collateral vessels. It is generally believed that an increase in the circulating levels of these gastrointestinally derived vasoactive agents in cirrhosis and portal hypertension may be responsible for peripheral vasodilatation and splanchnic pooling characteristic of this condition. These haemodynamic changes in cirrhosis would result in a decrease in the effective blood volume and therefore cause an increase in the sympathetic nervous system activity and activation of the renin-angiotensin axis, thereby inducing renal vasoconstriction. ${ }^{36}$ In addition, vasoconstrictor substances (leukotrienes and thromboxane $\mathrm{B}_{2}$ ) also enter the systemic circulation by a combination of PSS and hepatic dysfunction, further contributing to renal vasoconstriction. ${ }^{37}$ However, in acute liver failure, the duration of the disease has been usually considered to be too short for the development of a substantial collateral circulation. Therefore, it has been assumed that the gastrointestinal derived vasoactive agents responsible for the alterations in renal haemodynamics and function reach the circulation primarily as a result of impaired hepatocyte function. ${ }^{1}$ The results of this study clearly show that in acute liver failure, there is a large increase in intrahepatic PSS which may be a major mechanism whereby vasoactive agents reach the systemic circulation. This observation is supported by a significant correlation between intrahepatic PSS and the observed alterations in renal blood flow. Furthermore, the observation that intrahepatic PSS is markedly increased in acute liver failure has important potential therapeutic benefits. Thus administration of vasoactive drugs which markedly affect intrahepatic haemodynamics and which may decrease intrahepatic PSS may ameliorate not only perturbations in renal blood flow and function but also other abnormalities characteristic of this syndrome such as hepatic encephalopathy and systemic circulatory abnormalities.

In summary, the results of this study suggest that increased intrahepatic portal-systemic shunting and hepatocyte impairment may initiate a chain of events causing alterations in the systemic levels of vasoactive agents which culminate in alterations in renal haemodynamics and function.
This work was supported by a grant from the Mersey Kidney Research Fund. The work was presented at the Annual Meeting of the Surgical Research Society, Manchester, July 1995, and published in abstract form in the British fournal of Surgery $(1995 ; 82: 1565-6)$.

1 Moore K, Taylor G, Ward P, et al. Aetiology and management of renal failure in acute liver failure. In: Wilstanding and better therapy. London: Miter Press, 1991:4753.

2 Wilkinson SP, Blendis LM, Williams R. Frequency and type of renal and electrolyte disorders in fulminant hepatic failure. $B M \mathcal{F}$ 1974;1:186-9.

3 Gaurner F, Hughes RD, Gimson AES, et al. Renal function Gaurner F, Hughes RD, Gimson AES, et al. Renal function
in fulminant hepatic failure: haemodynamics and renal in fulminant hepatic failure: haemo

4 Wilkinson SP, Arroyo VA, Macdie H, et al. Abnormalities of sodium excretion and other disorders of renal function in fulminant hepatic failure. Gut 1971;17:501-5.

5 Bihari DJ, Gimson AE, Williams R. Cardiovascular pulmonary and renal complications of fulminant hepatic failure. Semin Liver Dis 1986;6:119-28.

6 Epstein M, Berk DP, Hollenberg NK, et al. Renal blood flow in the patient with cirrhosis. The role of active vasoconstriction. Am f Med 1970;49:175-85.

7 Hecker R, Sherlock S. Electrolyte and circulatory changes in terminal liver failure. Lancet 1956;ii:1121-5.

8 Bihari DJ, Gimson AE, Watson M, et al. Tissue hypoxia during fulminant hepatic failure. Crit Care Med 1985;13: during fuln

9 Shoemaker WC, Appel PL, Kram HB. Haemodynamics and oxygen transport: effects of dobutamine in critically ill general surgical patients. Crit Care Med 1986;14:1032-7.

10 Shoemaker PT, Cain SM. The concept of critical oxygen delivery. Intensive Care Med 1987;13:223-9.

11 Benoit JN, Granger DN. Splanchnic haemodynamics in chronic portal hypertension. Semin Liver Dis 1986;6:28798.

12 Sherlock S. Vasodilatation associated with hepatocellular disease; relation to functional organ failure. Gut 1990;31: 365-7.

13 Benoit JN, Barrowman SA, Harper SL, et al. Role of humoral factors in the intestinal hyperaemia associated with chronic portal hypertension. Am f Physiol 1984;247: G6486-93.

14 Chirito E, Lister C, Chang TMS. Biochemical, haematological and histological changes in a fulminant hepatic faillogical and histological changes in a fulminant hepatic fail-
ure rat model for artificial liver assessment. Artif Organs ure rat model

15 Yates J, Nott DM, Maltby PJ, et al. A novel method of determining portal systemic shunting using biodegradable ${ }^{99 \mathrm{~m}} \mathrm{Tc}$ albumin microspheres. HPB Surg 1995;8:1-10.

16 McDevitt DG, Nies AS. Simultaneous measurement of cardiac output and its distribution with microspheres in the rat. Cardiovasc Res 1976;10:494-8.

7 Desmond DV, James R, Shenker S, et al. Preservation of glucuronidation in carbon tetrachloride induced acute liver injury in the rat. Biochem Pharmacol 1981;30:993-9.

18 Wensing G, Sabra R, Branch RA. Renal and systemic haemodynamics in experimental cirrhosis in rats: relation to hepatic function. Hepatology 1990;12:13-18.

9 Decker K, Keppler D. Galacatosamine induced liver injury. Prog Liver Dis 1974;4:183-97.

20 Hepner GW, Vesell ES. Quantitative analysis of hepatic function by breath analysis after oral administration of function by breath analysis after oral administratio
$\left[{ }^{14} \mathrm{C}\right]$ aminopyrine. $N$ Engl $\mathcal{M}$ Med 1974;291:1384-7.

21 Reichen J, Arts B, Shafroth U, et al. Aminopyrine $\mathrm{N}$-demethylation by rats with liver cirrhosis. Gastroenterology 1987;93:719-26.

22 Epstein M, Schneider N, Befeler B. Relationship of systemic and intrarenal haemodynamics in cirrhosis. F Lab Clin Med 1977;89:1175-87.

23 Ring-Larson H, Pallazo U. Renal failure in fulminant hepatic failure and cirrhosis: a comparison between incidence, types and prognosis. Gut 1981;22:585-91.

24 Garner F, Gimson AES, Hughes RD, et al. Renal function in fulminant hepatic failure: haemodynamics and renal prostaglandins. Gut 1987;28:1643-7.

25 Wilkinson SP, Arroyo VA, Mode $\mathrm{H}$, et al. Abnormalities of sodium excretion and other disorders of renal function in fulminant hepatic failure. Gut 1976;17:501-5.

26 Chew MC, Karma RR, Williams HS, et al. Renal and intrarenal blood flow in cirrhosis of liver. Lancet 1971;ii:504-10.

27 Weldon J, Alexander JAM, Williams R. Central venous Weldon J, Alexander JAM, Williams R. Central venous
monitoring and local blood flow. Proceedings of the 11th BSG-SK\&F International Workshop. In: Williams R, Hughes RD, eds. Acute liver failure: improved understanding and better therapy. London: Miter Press, 1991.

28 Anderson RJ, Crew RE, McDonald TM, et al. Mechanisms of portal hypertension-induced alterations in renal haemodynamics, renal water excretion and rennin excretion. $f$ Clin Invest 1976;56:964-70

29 Ring Larsen H, Hess B, Stigsby B. Effect of portal systemic nastomosis on renal haemodynamics in cirrhosis. Gut 1976;17:856-60.

30 Wensing G, Sabra R, Branch RA. The onset of sodium retention in experimental cirrhosis in rats is related to its retention in experimental cirrhosis in rats is related to its
critical threshold of liver function. Hepatology 1990;11: 779-96.

31 Wensing G, Branch RA. Phenobarbital influences the development of sodium retention in liver disease induced by bile duct ligation in the rat. Hepatology 1990;11:773-8. 
32 Espinel CH, Said SI, Maclouf GM. Different effects of peptide homologues, VIP and glucagon on renal transport and haemodynamics. Clin Res 1976;24:36.

33 Hortnagl H, Lenz K, Singer EA, et al. Substance P is markedly increased in plasma of patients with hepatic coma. Lancet 1984;i:480-3.

34 Moore KP, Ward P, Taylor G, et al. Systemic and renal production of thromboxane $\mathrm{A}_{2}$ and prostacyclin in decompen sated liver disease and hepatorenal syndrome. Gastroenterology 1991:100:1069-77.

35 Wilk 1991,100:1069-77. impairment an impairment and haemorhagic diathesis to endotoxaemia in fulminant hepatic failure. Lancet 1974;i:521-4.

36 Schelling JR, Linas SL. Hepatorenal syndrome. Semin Nephrol 1990;10:565-70.

37 Lang F, Gerok W, Haussinger D. New clues to the pathophysiology of hepatorenal failure. Clin Invest 1993;71:93-7.

\section{Call for Patients with Familial Pancreatic Disease: The EUROPAC Register}

We are establishing a national UK register (EUROPAC) of families with hereditary pancreatitis, familial pancreatic cancer and where pancreatic cancer has occurred as part of a familial cancer syndrome. This collaboration in Liverpool is between the Department of Clinical Genetics ( Dr Ian Ellis) and the Academic Department of Surgery (Professor John Neoptolemos). The data and samples are collected by behalf of ESPAC (the European Study Group for Pancreatic Cancer), Professor Markus Büchler, Berne, and Professor Hans Beger, Ulm. The study will collaborate with Dr David Whitcomb of the Midwest Multicenter Pancreatitis study group in the United States. We aim to recruit families who are prepared to donate blood for DNA studies. We hope to gain a clearer understanding of the genetic relationship between hereditary pancreatitis and familial pancreatic cancer, and develop screening protocols for individuals at risk.

Hereditary pancreatitis is associated with a mutation in the recently identified cationic trypsinogen gene. This mutation renders the enzyme active within the pancreas, leading to autodigestion. Individuals with recurrent pancreatitis have a greatly increased risk of developing pancreatic cancer, and there is some evidence that DNA analysis of cells from pancreatic fluid may be valuable in detecting premalignant changes which can predict the development of pancreatic adenocarcinoma.

The criteria for inclusion in the study are as follows:

- Hereditary pancreatitis: Three relatives with chronic pancreatitis in the absence of ethanol dependence, hypercalcaemia, or an obstructive cause.

- Familial pancreatic cancer: Two first degree relatives with pancreatic adenocarcinoma. Three or more relatives with pancreatic ductal adenocarcinoma. Pancreatic ductal adenocarcinoma in any two relatives where the sum of their ages is less than 110 years.

- Other familial cancer syndromes: A single documented pancreatic ductal adenocarcinoma in any family with an established familial cancer syndrome-for example, BRCA2, FAMMM, A-T, HNPCC, or FAP.

If you know of any suitable families who may be interested in joining the study, please contact: Fiona McRonald, Clinical Genetics, Alder Hey Children's Hospital, Eaton Road, Liverpool L12 2AP. Tel: 01512525905.

Thank you for your help. 